\title{
TRIBUTOS AL MEDIO AMBIENTE: FINALIDAD EXTRAFISCAL Y LA ACTIVIDAD EMPRESARIAL EN ARGENTINA
}

\author{
Gastón Vidal ${ }^{1}$
}

\section{Resumen}

En el presente trabajo se analizará una de las cuestiones que se aborda bastante poco en el derecho argentino, que es la temática de la utilización del tributo con una finalidad extrafiscal, ello es no con el fin estricto de recaudar, sino de regular la actividad económica y empresarial, con el fin de proteger determinados bienes jurídicos que el Estado estima deben tener lugar en un determinado momento, o desalentar determinadas conductas o hacer responsable a ciertos sujetos de la actividad que llevan a cabo. Como se adelantó, se abordará la experiencia en la República Argentina con respecto a la aplicación de ciertos tributos, relacionada en particular con la tributación con la citada finalidad al medio ambiente en general y, en particular frente a la ardua problemática de los residuos o basura y envases que en sus diversas formas generan los agentes que intervienen en la actividad económica y empresarial. El planteo, que intenta ser un punto de partida para enriquecer un debate que aún resta que sea transitado, esto es si los tributos con finalidad extrafiscal pueden contribuir a colaborar en el complejo problema de la protección del medio ambiente y la disminución de la contaminación, así como también a que los actores involucrados no solo sean parte de la problemática sino que también colaboren con la solución. Con ese punto de partida, se desarrollarán los aspectos relevantes del trabajo.

Palabras clave: Tributos, Medio Ambiente, Actividad Empresarial.

$1 \quad$ Especialista en Derecho Tributario. Abogado. Docente Investigador de la Universidad de Palermo. Email: gvidalquera@yahoo.com.ar 


\section{Abstract}

This paper will analyze one of the issues that is dealt with very little in Argentine law, which is the issue of the use of tax for a purpose other than taxation, this is not with the strict purpose of collecting, but to regulate economic and business activity, in order to protect certain legal assets that the State believes should take place at a given time, or discourage certain conduct or make certain subjects responsible for the activity they carry out. As mentioned above, the experience in the Argentine Republic with respect to the application of certain taxes will be discussed, related in particular to taxation with the aforementioned purpose to the environment in general and, in particular, in the face of the arduous problem of waste or garbage and containers generated in their various forms by agents involved in economic and business activity. The proposal, which tries to be a starting point to enrich a debate that still remains to be transited, this is if the taxes with extrafiscal purpose can contribute to collaborate in the complex problem of the protection of the environment and the reduction of pollution, as well as that the actors involved are not only part of the problem but also collaborate with the solution. With this starting point, the relevant aspects of the work will be developed.

Keywords: Taxes, Environment, Business Activity.

\section{Introducción}

Los tributos son prestaciones coactivas u obligatorias, en dinero usualmente o en especie en casos excepcionales, que exige el Estado en virtud de su poder de imperio por medio de una ley, ya que en este tema rige con especial énfasis el principio de legalidad. El poder de imperio se lo considera como el conjunto de potestades atribuidas por el ordenamiento jurídico a determinadas instituciones públicas, que se relacionan con la soberanía, y en particular en lo que interesa a este trabajo, el poder tributario, dado por la posibilidad de establecer los citados tributos. Son detracciones obligatorias que proceden o se sacan, como se asentó, en dinero usualmente, del patrimonio personal de los particulares. La República Argentina ha tomado una clasificación tripartita de los tributos, compartida tanto por la doctrina especializada en la materia como por la Corte Suprema de Justicia 
de la Nación, al utilizar en forma unánime la clasificación en impuestos, tasas y contribuciones especiales.

Los impuestos son prestaciones obligatorias, en dinero o en especie, que el Estado, en ejercicio de la utilización de su poder de imperio, exige, en virtud de ley, sin obligarse a una contraprestación respecto del contribuyente en forma directa y concreta. Se ha dicho que:

Por medio del impuesto son retribuidos servicios indivisibles prestador por el Estado, es decir, aquellos que si bien son útiles a toda la comunidad, resulta imposible, en la práctica, efectuar su particularización en lo atinente a personas determinadas (p. ej: defensa...). (Manual de Derecho Tributario, Catalina García Vizcaíno, Abeledo Perrot, 2017, Página 37)

Según el MCTAL -OEA/BID, art. 15- el impuesto "Es el tributo cuya obligación tiene como hecho generador una situación independiente de toda actividad estatal relativa al contribuyente". Los impuestos gravan una manifestación de capacidad contributiva (según la técnica tributaria existen tres: renta, patrimonio y consumo) sin que el Estado "de nada cambio u ofrezca algo por su cobro" ni se comporte de determinada manera con relación al contribuyente, más allá de la financiación de un servicio indivisible como la defensa, salud, educación, etc. Se considera que si se respetan los fines de la tributación y de capacidad contributiva es una de las formas más justas y equitativas de imposición. Los impuestos deben ser utilizados para financiar aquellos servicios y bienes que el Estado debe prestar, según su concepción y momento temporal, en forma directa y propia, sin la intervención de terceros.

Por su parte, las tasas son prestaciones obligatorias, en dinero o en especie, que el Estado, en ejercicio de su poder de imperio, exige, en virtud de ley, por un servicio o actividad estatal que se particulariza o individualiza en el obligado al pago. Lo esencial en las tasas es el servicio que es divisible, ya que está determinado e individualizado en un sujeto.

En las XV Jornadas del Instituto Latinoamericano de Derecho Tributario del año 1991, que tuvo lugar en Venezuela, Caracas, se concluyó que:

Es de la esencia de la tasa que el servicio estatal que constituye su presupuesto de hecho sea prestado efectivamente por la Administración al contribuyente, aun cuando éste se resista a recibirlo. La prestación efectiva del servicio al contribuyente es uno de los elementos caracterizadores 
más importantes para distinguir la tasa de las otras especies tributarias, particularmente el impuesto.

La Corte Suprema de Justicia de la Nación tiene dicho en su doctrina jurisprudencial que mantuvo invariable con el paso del tiempo que “... un requisito fundamental respecto de las tasas, como es que al cobro de dicho tributo debe corresponder siempre la concreta, efectiva e individualizada prestación de un servicio referido a algo no menos individualizado del contribuyente...". Por ejemplo se paga la tasa de justicia al recibir el servicio por esa actividad, la tasa de alumbrado, barrido y limpieza que deben abonar los titulares de inmuebles, entre muchas otras, y la principal tasa que pagan las empresas, por inspección de seguridad e higiene, por tal servicio estatal.

Finalmente, las contribuciones especiales han sido definidas como "toda prestación obligatoria, en dinero o en especie, que el Estado, en ejercicio de su poder de imperio, exige, en virtud de ley, por beneficios individuales o de grupos sociales derivados de la realización de obras o gastos públicos, o de especiales actividades estatal. El Modelo de Código Tributario América Latina dispone en el artículo 17 que "el producto no debe tener un destino ajeno a la financiación de las obras o las actividades que constituyen el presupuesto de la obligación”.

Se dividen en contribuciones especiales de mejoras que son las que se caracterizan por el beneficio que surge de la realización de una obra pública (pavimentación, etc) y las contribuciones parafiscales que son las que se recaudan para asegurar el funcionamiento de ciertos entes públicos o semipúblicos y que son un recurso que la ley les da para funcionar. En las contribuciones de mejoras por la realización de una obra pública el límite para cobrar ese el beneficio por la revalorización de la misma que se le cobra a los frentistas o titulares de dominio. No puede superarse ese límite, caso contrario sería inconstitucional. Sobre las parafiscales se ha dicho que tienen las siguientes características: a) son ingresos públicos que no suelen ser integrados en los presupuestos generales del Estado, b) son recursos afectados al financiamiento de ciertos entes estatales y c) suele haber una tendencia a sustraerlas del cumplimiento de los principios jurídicos de los tributos, en especial del reserva de ley, con la excusa que no poseen naturaleza tributaria 
En resumen respecto a las especies tributarias, en el impuesto se grava una manifestación de capacidad contributiva sin "nada a cambio", en la tasa necesariamente el Estado debe prestar un servicio y en la contribución especial el sujeto pasivo que las paga debe recibir un beneficio para el contribuyente u obligado al pago.

Se analizará a continuación la finalidad extrafiscal en las especies tributarias relacionadas con fines ambientales y como han sido utilizadas en nuestro país, en algunos casos relevantes, sin pretender agotar todos los institutos que se aplicaron en la materia.

Cabe adelantar, que el tributo puede ser un poderoso instrumento de política económica, social y para ordenar o desalentar conductas o castigar otras por parte del Estado. La materia medio ambiental no está ajena a la posibilidad de utilizar este instrumento para la política económica y para que los mismos cumplan con su finalidad y sean eficaces, se debe reducir la posibilidad de traslación de modo que la efectiva incidencia recaiga sobre el sujeto que participa en la contaminación en forma activa, a fin de modificar o atenuar sus comportamientos.

Como es sabido, los tributos tienen como principal función la de recaudar y acercar importes dinerarios al Estado (finalidad fiscal) para poder cumplir con sus objetivos públicos, como la salud, defensa, educación, etc. Pero los tributos también pueden tener finalidad extrafiscal, que está relacionada con desalentar actividades para cumplir con un determinado propósito o cometido (caso de los tributos para la protección del medio ambiente y similares), en cuyo caso la recaudación debería ser nula o casi nula. Se ha dicho con claridad que "los intentos de usar impuestos con fines extrafiscales muchas veces desnaturalizan su esencia, como, p.ej., la utilización indiscriminada de tributos con fines ecológicos que terminan frecuentemente poniendo un precio a la polución ambiental.”

Para la Corte Suprema de Justicia de la Nación ha dicho que "el poder impositivo constituye un valioso instrumento de regulación, complemento necesario del principio constitucional que prevé atender al bien general, al que conduce la finalidad ciertamente extrafiscal de impulsar la expansión de las fuerzas económicas".

En conclusión, la finalidad extrafiscal de los tributos se utiliza como mecanismos o instrumentos de política financiera, económica y social para 
impulsar, proteger o inhibir que se realicen ciertas actividades en las cuales el Estado centra su interés. Se abordará su uso, como ya se adelantó, en cuestiones de protección del medio ambiente en líneas generales.

\section{El régimen constitucional argentino - La distribución del poder tributario}

Cabe considerar que la República Argentina es un país federal, formado por el Estado Nacional, por veintitrés provincias y la Ciudad Autónoma de Buenos Aires, y por más de mil seiscientas municipalidades, que están enclavados dentro de cada una de las provincias. De acuerdo a la Constitución Nacional, las provincias son preexistentes al Estado Nacional y se unieron para formar el mismo.

Respecto al poder tributario, los recursos que se aplican en el comercio exterior (tributos aduaneros) son exclusivos y excluyentes aplicados por el Estado Nacional. Adicionalmente, se separa la imposición directa e indirecta, siendo la primera excepcional para el Estado Nacional, por ende habitual para las provincias, e indirecta concurrente para el Estado Nacional y las provincias.

Por su parte, la ley 23. 548 de coparticipación federal de impuestos es la actualmente vigente desde el año 1987, dispone como se distribuye el poder tributario para evitar o apaciguar la doble o múltiple imposición en la Argentina, la cual es perfectamente constitucional. Se trata de un régimen de coparticipación, con rango constitucional a partir de 1994, por medio del cual, el Estado Nacional recauda y coparticipa a las provincias su producido, las que, por sí y sus municipios se abstienen de cobrar sobre manifestaciones de capacidad contributiva que pueden cobrar (renta, patrimonio y consumo). Quedan fuera de las obligaciones emergentes del régimen los impuestos provinciales clásicos (ingresos brutos, sellos, embarcaciones deportivas y patentes de los automotores, inmobiliarias y transmisión gratuita de bienes). Asimismo, todos los niveles de gobierno pueden cobrar "tasas retributivas de servicios efectivamente prestados".

Es por ello, como veremos que principalmente las municipalidades han establecido tasas retributivas de servicios con finalidad extrafiscal relacionados con la contaminación en general, y en particular en resguardo del medio ambiente y la Ciudad Autónoma de Buenos Aires tiene vigentes impuesto con esa finalidad, así como también otras provincias que han 
utilizado los impuestos como esa herramienta. Se analizarán si esas finalidades extrafiscales se cumplieron o no en casos concretos en materia de medio ambiente, tanto con la basura como el tratamiento de los envases y demás productos que generan las empresas; así como también la responsabilidad que les cabe a los sujetos que intervienen en tales cuestiones.

\section{Breve referencia al problema de la basura}

El problema de la basura es uno de los más importantes que tienen que afrontar los países en el tema de la contaminación. Se estima que en la República Argentina se genera una tonelada de basura cada dos segundos. Los procesos industriales modernos dieron lugar a la generación de una infinidad de materiales sintéticos que, al no degradarse en forma natural, se acumulan en el ambiente y ocasionan serios perjuicios para la población y para el desarrollo de los países. La acumulación de basura o su lenta descomposición produce graves efectos sobre el entorno y la calidad de vida de los habitantes.

Las nuevas tendencias en el tema consideran que quien participa en el proceso de contaminación debería ser involucrado y tomar parte en el proceso de transporte y tratamiento del mismo. Por ejemplo en el caso de los envases o envoltorios, botellas, latas, etc, las nuevas orientaciones estiman que debe involucrarse a su productor o comercializador a ser responsable de su tratamiento luego de que los mismos sean utilizados. En ese sentido, existe un proyecto de ley, con trámite parlamentario, de Responsabilidad Extendida delProductorqueestablecelospresupuestosmínimosde protecciónambiental para la gestión ambiental de los envases y sus residuos. Se incluye en esa ley a todos los envases y sus residuos, que luego de su utilización o consumo, sean susceptibles de ser gestionados como residuos domiciliarios. Se dispone que los productores constituyan asociaciones de alcance nacional para la gestión de sus residuos de envases, estableciendo un "Sistema de Gestión Integral de Residuos de Envases".

Desde el punto de vista de la generación de residuos y su posterior tratamiento, la finalidad extrafiscal de la tributación ambiental puede ser una herramienta útil que cumpla con el cometido propuesto, así como también en el caso del manejo de la basura en general. 


\section{Tributos medioambientales: solo un precio?}

Los tributos ambientales tienen cuatro aspectos esenciales para ser considerados como tales: pertenecen a la categoría tributos, finalidad de carácter extra-fiscal (ecológica o protección del ambiente), ausencia de naturaleza sancionatoria y falta de necesidad que exista una asignación ecológica de los fondos recaudados.

La finalidad extrafiscal en materia ambiental está dada por un principio que se conoce como "quien contamina paga" o, como se sostuvo, con las modernas tendencias del deber de colaborar o estar involucrado en el proceso por la contaminación a raíz de la realización de actividades de prestación de servicios o venta de productos que son introducidos al mercado. Es decir que prevalece esa situación y debe considerarse que cuando menos se recauda por parte de esta clase de tributos, en mejor manera se está cumpliendo con la finalidad extrafiscal, ya que quiere decir que no se está contaminando tanto o se están aplicando los mecanismos para reducir la misma, o también por el hecho de contemplar la participación en los costos del proceso de manejo o disposición final de los residuos. Caso contrario, los contribuyentes considerarán que tienen "vía libre" para contaminar pagando simplemente un "precio" para ello, con una evidente finalidad fiscal.

A continuación se analizarán algunos ejemplos relevantes de la tributación ambiental en la Argentina, con especial referencia a la generación de los residuos y a la contaminación en general, para ver si actúan como un "precio o costo" por no contaminar o si realmente estamos frente a tributos con verdadera finalidad extrafiscal. También se hará referencia de otros casos en donde se vislumbra que con el argumento de disponer una tributación al medio ambiente se utilizó con finalidad claramente recaudatoria.

\section{Ciudad Autónoma de Buenos Aires: el caso del impuesto a la "basura" y el impuesto a los "escombros"}

En el año 2005, la Ciudad Autónoma de Buenos Aires dictó la ley 1854 denominada de "Basura Cero" por medio de la cual estableció en el Artículo $1^{\circ}$ :

La presente ley tiene por objeto establecer el conjunto de pautas, principios, obligaciones y responsabilidades para la gestión integral de los residuos sólidos urbanos que se generen en el 
ámbito territorial de la Ciudad Autónoma de Buenos Aires, en forma sanitaria y ambientalmente adecuadas, a fin de proteger el ambiente, seres vivos y bienes. En este sentido la Ciudad adopta como principio para la problemática de los residuos sólidos urbanos el concepto de Basura Cero.

Asimismo, se fueron dando instrumentos tributarios relacionados con la tributación al medio ambiente con la finalidad de buscar ese objetivo. Los tributos que se hará referencia a continuación fueron establecidos en el Título VI del Código Fiscal expresamente como "Gravámenes ambientales", con lo cual su naturaleza tributaria y objeto establecido por el legislador son palmariamente indudables.

En efecto, en el año 2010 la Ciudad Autónoma de Buenos Aires-que es la capital de la República Argentina-, en el marco de sus objetivos de reducir la generación de basura, estableció el denominado "Impuesto a la "Generación de Residuos Sólidos Urbanos Húmedos no Reciclables" comúnmente denominado como "Impuesto a la Basura". Ese impuesto se cobra por la generación de residuos sólidos urbanos húmedos no reciclables ("basura"), siendo sujetos pasivos y responsables de su ingreso los generadores especiales de los residuos.

De acuerdo a la ley tarifaria 2018 (5914) se establece un canon anual por litros diarios desde 240 a $\$ 17.100$ y más de 4000 el canon anual es de \$ 679.740 para cada uno de los lugares físicos.

Están exentos los contribuyentes que en ninguno de los lugares físicos que tengan (sucursales, bocas de expendio, etc) generen residuos que alcancen los 1000 litros y quienes sean considerados "Generadores Especiales de Residuos sólidos" que estén inscriptos en el programa de generadores privados de la Coordinación Ecológica Área Metropolitana Sociedad del Estado (CEAMSE) debiendo costear el transporte y disposición final de la fracción húmeda de residuos por ella producida. Si bien se genera esta obligación de costear el transporte de la basura hasta su disposición final, para lo cual se lo exime del impuesto, entiendo que no se cumple con la finalidad extrafiscal ya que el sujeto por el hecho de encargarse de pagar el tratamiento y disposición final de los residuos, no debe pagar el impuesto, pero puede seguir generando la basura que quiera. De esa manera, más allá 
de la loable finalidad de quien genera la basura se haga cargo, lo concreto es que pagando por la generación de la misma, se termina el tema.

Por su parte, la Ciudad Autónoma de Buenos Aires también creó el "Impuesto a la Generación de Residuos Áridos" cuya generación, así como los restos de demolición y construcción pagan el impuesto. Son responsables del pago en forma solidaria los propietarios y/o consorcios de propietarios, las empresas constructoras y el profesional actuante en la obra o demolición y se abona por cada metro cuadrado (m2). Están exentos únicamente los generadores que realicen construcciones de viviendas de interés social desarrolladas o financiadas por organismos nacionales o del Gobierno de la Ciudad de Buenos Aires. De acuerdo a la ley tarifaria 2018 (5914) se establece un importe de $\$ 114$ por metro cuadrado (m2) el impuesto que se debe abonar. Entiendo quesibiense lo incluye como un "gravamen ambiental" pero lo único que hace es cobrar sobre los restos de demolición y por metro cuadrado por lo que no cumple con ninguna finalidad extrafiscal de intentar se generen menos escombros, ya que el sujeto lo abona y se termina el asunto sin que haya intención de reducir la generación de los mismos.

Se ha dicho con claridad que "... será necesario vigilar el cumplimiento por parte del Estado del fin extrafiscal por el cual son creados estos tributos, pues puede correrse el riesgo de que, bajo la excusa medioambiental, se pretenda aumentar la recaudación a fin de cubrir las necesidades financieras existentes".

En ambos impuestos, estamos frente algo parecido al "precio" que se paga por sea, generar basura o escombros, sin que se pueda vislumbrar la finalidad extrafiscal en materia de gravámenes ambientales, para que se contamine menos, más allá de la posibilidad de solicitar la reducción tributo.

Algunos ejemplos de Municipios con tasas ambientales a la contaminación por envases y residuos) San Fernando - Provincia de Buenos Aires

La Municipalidad de San Fernando por intermedio de su Ordenanza Fiscal 12.210/17 vigente para el 2018 dispone en el artículo 360 la "Tasa por Comercialización Envases no retornables y afines", cuyo hecho imponible son

Por los servicios municipales de protección ambiental, correspondiente a la implementación de programas de concientización, acopio, reciclado, 
tratamiento, servicios de recolección diferencial y disposición especial de envases no retornables y material desechable, tales como botellas PET, multicapa, aerosoles, latas y otros envases no retornables de características similares, así como también de pañales descartables". Se establece un importe por cada botella no retornable $(\$ 0,43)$, envase $(\$ 0,09)$, lata de bebida (\$ $0,15)$, envase de aerosol $(\$ 0,20)$, pañal descartable $(\$ 0,09)$ y deben pagar las tasas las personas físicas o jurídicas titulares de actividades económicas de venta minorista o mayorista en el Partido de San Fernando. El artículo 365 dispone que

Los sujetos obligados que establezcan sistemas de acopio de la modalidad de puntos verdes, para la recepción y envío a la adecuada recuperación o tratamiento para reciclado de los productos por ellos comercializados podrán, previa acreditación de la correcta gestión dada a dichos residuos, en el marco de sistemas industriales de reciclaje, solicitar la reducción de la Tasa en la proporción a la cantidad y tipo de material recibido y reciclado". Si bien se dispone la reducción de la Tasa si los sujetos cuentan con sistemas de reciclaje, la finalidad parece más fiscal ya que se le adicionará al precio de los productos que se vendan el monto de la tasa, no pareciendo una solución al complejo tema que se analiza. Funcionaría como un tributo indirecto que se trasladaría al precio.

\section{Bahía Blanca - Provincia de Buenos Aires: la "Tasa ambiental"}

La Municipalidad de Bahía Blanca tiene en el art. 271 de la Ordenanza Fiscal vigente tiene regulada la "Tasa Ambiental":

Por los servicios de control, monitoreo, prevención, coordinación de planesdemonitoreo con planes deevaluación deriesgo, planesdecontingencia y cualesquiera otro, destinados directa o indirectamente a la preservación y optimización de la calidad ambiental y al desarrollo e implementación de planes de respuesta ante emergencias tecnológicas, se establece la presente Tasa Ambiental, la cual se fijará en función del nivel de complejidad ambiental del emprendimiento o actividad industrial desarrollada en el partido de Bahía Blanca". El art. 273 dispone que "la base imponible del presente gravamen estará constituida por el nivel de complejidad ambiental que presente el emprendimiento o actividad, siguiendo los parámetros establecidos en la Ordenanza Impositiva". La Ordenanza Impositiva 2018 dispone en el artículo 54 una fórmula complejo de cobro y dispone que "deberán abonar... 
teniendo en cuenta que el valor máximo de esta no podrá ser superior del uno por mil de la facturación del producto o proceso desarrollado en el partido de bahía blanca". Se cobra una tasa pero no se indican los servicios con claridad relacionados con la calidad y protección del medio ambiente, ya que los servicios son genéricos.

\section{San Carlos de Bariloche - Provincia de Río Negro: la "ECOTASA" ¿el impuesto al turista por contaminar?}

Finalmente, hago referencia a un ejemplo de un caso en que la tributación al medio ambiente, es claramente utilizada con una finalidad única de recaudar.

La Ordenanza 2620-CM-15 creó en el Título XIX artículo 362 la denominada "ECOTASA" siendo el hecho imponible:

Es la contraprestación que la Municipalidad exige a los turistas que pernocten en esta ciudad, cualquiera sea el tipo y categoría del establecimiento de alojamiento turístico, por los servicios turísticos y de infraestructura turística, directos e indirectos y aquellos potenciales que la Municipalidad presta en conservación patrimonial, mejoramiento y protección de sitios y paseos turísticos, comprensivos de ingresos y portales al a ciudad, sendas, accesos a lagos y sus playas, ríos y montañas, puntos panorámicos, miradores, servicios de información y atención turística, baños públicos, y todo otro servicio turístico, garantizando un turismo sustentable desde el punto de vista social, ambiental y económico". La base imponible "está constituida por un monto fijo por día de pernocte, que abonará cada turista en la Ciudad de San Carlos de Bariloche, en el establecimiento turístico que se aloje.

De acuerdo al artículo 114 de la Ordenanza 2925-CM-17 se fijan los siguientes valores para el 2018 que deben percibir los establecimientos de alojamiento turístico: 


\section{Tabla 1}

Valores para el 2018 de los establecimientos de alojamiento turístico

\begin{tabular}{cc}
\hline Tipo y categoría & $\begin{array}{c}\text { Valor fijo por noche por } \\
\text { persona }\end{array}$ \\
\hline Alojamiento 1 estrella & $\$ 10$ \\
Alojamiento 2 estrellas & $\$ 20$ \\
Alojamiento 3 estrellas & $\$ 30$ \\
Alojamiento 4 estrellas & $\$ 45$ \\
Alojamiento 5 estrellas & $\$ 60$ \\
Alojamiento turismo estudiantil & $\$ 30$ \\
Alojamiento sin categorizar & $\$ 10$ \\
Campings y refugios & $\$ 5$ \\
\hline
\end{tabular}

Creación Propia.

Pese al esfuerzo de describirlo como una tasa, y lo bajo del importe que se cobra, es claro que no tiene un servicio individualizado en el turista, y al cobrarse en relación al alojamiento, es análogo al impuesto al valor agregado que se cobra a nivel nacional por las locaciones y prestaciones de servicios en general. Su función recaudatoria es manifiesta y se está cobrando un "impuesto al turista" por usar los servicios de infraestructura turística que ofrece el municipio.

Incluso el actual presidente de la Nación, Mauricio Macri, indicó que demandarían municipio por considerar que cobraban un impuesto y no una tasa ya que no tiene servicio alguno.-

\section{Conclusiones}

Los tributos ambientales tienen en Argentina una mayoritaria finalidad fiscal de acuerdo a los casos que han sido analizados, que son una muestra de la situación en que se han manejado, encontrándose ausente o débil la presencia de finalidad extrafiscal de los mismos. Surge que, en principio, esencialmente la tributación ambiental tiene finalidad fiscal. 
La fiscalidad ambiental se debe orientar a internalizar el costo social en el empresario, comerciante, productores y consumidores, participando y haciéndose cargo de la responsabilidad que tengan en la generación de la contaminación en sus diversas formas y casos en que intervienen.

La finalidad extrafiscal de los tributos puede ser un instrumento adecuado para que los agentes económicos reduzcan la contaminación, en especial con la basura y los residuos, por intermedio de la mejora del tipo de materiales que usan, de participar en el tratamiento de los desechos que generan por los productos que venden, de contribuir a su tratamiento y disposición final, pero mejorando muchos aspectos como es en la actualidad en los que se limitan a pagar un "precio" por contaminar o generar basura, con las consecuencias que ello acarrea al medioambiente.

En la actualidad, no hay una política coordinada en temas tributarios ambientales, tanto a nivel Nacional, provincial y municipal, y los tributos vigentes no tienen finalidad extrafiscal, por lo que resta una regulación precisa que cumpla con esa finalidad para todos los agentes económicos en aras de lograr el objetivo propuesto.

Es necesario una política uniforme para las industrias y los agentes económicos en general, sumado ello a la necesidad de reafirmar el reciclado para la población y el desarrollo de la educación ambiental para toda la población.

No cabe esperar más, ya que el estado actual del planeta y el avance de la contaminación exigen de los Estados concretas regulaciones y de los agentes económicos reglas precisas en la materia.

Como sostuvo el poeta Víctor Hugo "Produce una inmensa tristeza pensar que la naturaleza habla mientras el género humano no la escucha". Es el momento y la agenda mundial exige tomar cartas en el asunto y utilizar todas las herramientas que estén al alcance para lograr con la finalidad planteada de protección al medio ambiente 


\section{Referencias}

García Vizcaíno, Catalina, Manual de Derecho Tributario, Editorial Abeledo Perrot, 2017.

Gustavo Naveira de Casanova, Finanzas Públicas y Derecho Financiero, Editorial Estudio, 2012.

https://www.cronista.com/responsabilidad/Produccion-de-basura-cual-esla-realidad-en-Argentina-y-que-se-podria-hacer-20180302-0075. html

www.senado.gov.ar/parlamentario/parlamentaria/380359/downloadPdf

El impuesto al fuego de la Provincia de Córdoba, ¿Tributo ambiental o recaudatorio?, Rodolfo Salasa Boiis enhttps://revistas.unc.edu.ar/index.php/refade/article/viewFile/11524/11962

https://www.rionegro.com.ar/bariloche/macri-demando-a-bariloche-por-la-aplicacion-de-la-ecotasa-AH3797323 